\title{
ВИЯВЛЕННЯ ПРОДУКТІВ БІОТРАНСФОРМАЦІЇ МІЛНАЦИПРАНУ В СЕЧІ ЗА УМОВ ТШХ-СКРИНІНГУ
}

Вступ. Тонкошарова хроматографрія (ТШХ) є найбільш доступним скринінговим підходом, який використовують у судовій токсикології. Для аналітичної діагностики отруєнь лікарськими препаратами методом ТШХ важливе значення має розробка умов виявлення в біологічних об'єктах як нативних сполук, так і продуктів їх біотрансорормації.

Мета дослідження - розробити методику ізолювання препарату антидепресивної дії "Мілнаципран" із сечі людини за наявності продуктів його біотрансформації і встановити умови їх виявлення методом тонкошарової хроматографії, придатні для проведення аналітичної діагностики інтоксикацій тимолептиками.

Meтоди дослідження. Дослідження проводили з пробами сечі людини, зібраними після прийняття разової терапевтичної дози мілнаципрану. Сечу піддавали кислотному гідролізу та екстрагували антидепресант і його метаболіти з деструктату хлорофформом з лужного середовища при рН 8-9. Супутні ендогенні домішки видаляли шляхом екстракції діетиловим етером з кислого середовища при рН 1. Для хроматографрічного дослідження екстрактів використовували чотири рухомі фрази, рекомендовані Міжнародною асоціацією судових токсикологів для ТШХ-скринінгу лікарських речовин, та хроматографрічні пластини Merk. Кольорові реакції проводили на шматочках хроматографрічних пластин з низкою найбільш поширених у хіміко-токсикологічному аналізі хромогенних реактивів. Метаболіти мілнаципрану ідентифріковували методом мас-спектрометрії електронного удару.

Результати й обговорення. Встановлено параметри хроматографрічної рухливості основного (N-дезетилмілнаципран) та мінорного (структури встановити не вдалось) метаболітів мілнаципрану, а також результати реакцій їх візуалізації хромогенними реактивами.

Висновки. Запропоновано умови ізолювання мілнаципрану та продуктів його біотрансфрормації із сечі людини. Розроблено методику виявлення нативної сполуки і метаболітів мілнаципрану в екстрактах із сечі методом ТШХ та кольорових реакцій після прийняття разової терапевтичної дози препарату. Методики рекомендовано для використання у практиці судової та клінічної токсикології.

КЛЮчОВІ СЛОВА: мілнаципран; хіміко-токсикологічний аналіз; біорідини; метаболіти; тонкошарова хроматографрія; кольорові реакції; мас-спектрометрія.

ВСТУП. Мілнаципран - $(1 R, 2 S)$-цис-2-(амінометил)-N,N-діетил-1-сренілциклопропанкарбоксаміду гідрохлорид, $є$ новітнім тимоаналептиком третього покоління, його фрармакологічний ефект опосередковується вибірковим інгібуванням зворотного захоплення серотоніну та норадреналіну [1]. Мілнаципран найбільше використовують у фрармакокорекції ендогенних депресій середнього і тяжкого ступенів. Особливістю його фрармакологічної дії $€$ відсутність помітного адренолітичного, холінолітичного та кардіотоксичного ефеектів, що дає підставу віднести вказаний препарат до антидепресантів першого ряду [2]. При передозуванні мілнаципран чинить кардіотоксичну дію та здатний викликати серотоніновий синдром [3]. Перший випадок (อ С. В. Баюрка, С. А. Карпушина, Е. Ю. Ахмедов, 2021. фратального передозування препаратом було зареєстровано у 2008 р., при цьому аналітична діагностика смертельного отруєння показала надзвичайно високий рівень мілнаципрану в артеріальній і периферичній крові, який становив 20 та 21,5 мг/л відповідно [4].

У літературі наведено дані про рівень терапевтичної концентрації мілнаципрану в плазмі крові людини, що становив 679 нг/мл [5], 0,1351,9 мг/л (нативна речовина) та 4,9 мг/л (сума нативної речовини і метаболітів) [6].

У процесі метаболічних перетворень в організмі людини мілнаципран не вступає у взаємодію із системою цитохрому Р-450, що відрізняє його від інших антидепресантів. При цьому препарат не утворює активних продуктів біотрансорормації, найбільша кількість виводиться 
нирками, близько 85 \% від прийнятої дози виводиться за 24 год. На 50-60 \% мілнаципран екскретується із сечею в незміненому стані, близько 20-30 \% - у вигляді кон'югату нативної речовини 3 кислотою глюкуроновою [6], 20 \% - як продукти кон'югації, переважно це мілнаципран карбамоїл-О-глюкуронід $[5,6]$ та $N$-дезетилмілнаципран (близько $8 \%$ [5]).

Наведені в літературі біоаналітичні методи визначення мілнаципрану здебільшого основані на використанні високоефективної рідинної хроматографрії (BEPX) з тандемним мас-спектрометричним детектуванням (BEPX-MC/MC) [7]. Однак інструментальна база методу BEPX-MC/MC не завжди доступна для вітчизняних токсикологічних лабораторій. У практиці судово-токсикологічних досліджень широко застосовують систему скринінгу на основі тонкошарової хроматографрії (ТШХ-скринінг). ТШХ-скринінг зауніверсальністю та селективністю перевершує імунохроматографрічний скринінг тає більш доступним, ніж BEPXабо газохроматограсрічний скринінг [5]. Однією з основних проблем, що виникають при токсикологічному дослідженні об'єктів біологічного походження на наявність лікарських речовин, $€$ суттєва нестача даних щодо параметрів хроматограсрічної рухливості продуктів їх біотрансорормації.

Мета дослідження - розробити методику ізолювання препарату антидепресивної дії "Мілнаципран" із сечі людини за наявності продуктів його біотранссрормації і встановити умови їх виявлення методом тонкошарової хроматографрії, придатні для проведення аналітичної діагностики інтоксикацій тимолептиками.

МЕТОДИ ДОСЛІДЖЕННЯ. Мілнаципран приймав чоловік віком 46 років, який не мав захворювань, зокрема всередину 4 таблетки препарату “Іксел" (25 мг) (що відповідало разовій терапевтичній дозі препарату [2]), після споживання їжі. Сечу збирали протягом 14 год окремими порціями по 50 мл, починаючи з п'ятої години після прийняття антидепресанту. Порції біологічної рідини об'єднували та піддавали кислотному гідролізу за такою методикою.

Методика. До 20,00 мл сечі додавали кислоту хлоридну концентровану 3 розрахунку 0,10 мл кислоти на кожні 2,00 мл біологічної рі- дини. Суміш нагрівали протягом 30 хв на киплячій водяній бані.

Отриманий гідролізат піддавали екстракційній очистці. Для цього його охолоджували, тричі збовтували в ділильній лійці 37 мл діетилового етеру протягом 5 хв кожного разу. Після розділення фраз органічний розчинник відокремлювали та відкидали. Кислий гідролізат, який залишився після видалення 3 нього домішок, підлуговували за допомогою $20 \%$ розчину натрій гідроксиду до рН 8-9, тричі екстрагували основу мілнаципрану хлороформом по 10,00 мл кожного разу. Отримані екстракти об'єднували, срільтрували крізь складчастий паперовий фрільтр, що містив 0,2 г безводного натрій сульсрату, та випаровували на водяній бані при температурі $40^{\circ} \mathrm{C}$ до видалення хлорофрорму. Сухий залишок розчиняли в 5,00 мл хлороформу, ретельно перемішували, переносили в мірну колбу місткістю 25,00 мл, доводячи тим же розчинником до зазначеного об'єму.

Під час попередніх дослідів з модельними розчинами мілнаципрану було вивчено його стійкість до обраних умов проведення кислотного гідролізу кон'югованих продуктів біотрансорормації в сечі. Контроль можливої появи продуктів кислотної деструкції цього препарату здійснювали методом ТШХ. При порівнянні хроматограм гідролізату і стандартного розчину мілнаципрану жодних додаткових плям не було відмічено.

Хроматограсрічні дослідження проводили 3 використанням пластин Merck. Хроматограми послідовно розвивали у двох рухомих фразах: хлороформ та етилацетат - метанол - $25 \%$ розчин амоній гідроксиду (85:10:5) (1) або метанол - $25 \%$ розчин амоній гідроксиду $(100: 1,5)$ (2), або циклогексан - толуен - діетиламін (75:15:10) (3), або толуен - ацетон - етанол $25 \%$ розчин амоній гідроксиду $(45: 45: 7,5: 2,5)(4)$. Отримані хроматограми проявляли за допомогою реактиву Драгендорфа, модифрікованого за Мун'є, або підкисленим розчином калій йодплатинату. Мілнаципран та продукти його біотранссрормації елюювали 3 пластин метанолом. Отримані елюати використовували для проведення кольорових реакцій (табл. 1, 2). Ідентифрікували метаболіти з використанням методу масспектрометрії: мас-спектрометр Varian 1200 L

Таблиця 1 - Показники хроматографічної рухливості мілнаципрану та продуктів його біотрансформації

\begin{tabular}{||c|c|c|c|}
\hline \hline \multirow{2}{*}{ Рухома фраза } & \multicolumn{3}{|c|}{ Значення $R_{\mathrm{f}}(\mathrm{n}=5 ; \mathrm{P}=0,95)$} \\
\cline { 2 - 4 } & мілнаципран & $N$-дезетилмілнаципран & мінорний метаболіт \\
\hline 1 & $0,32 \pm 0,03$ & $0,91 \pm 0,03$ & $0,11 \pm 0,03$ \\
\hline 2 & $0,27 \pm 0,03$ & $0,77 \pm 0,03$ & $0,07 \pm 0,02$ \\
\hline 3 & $0,06 \pm 0,02$ & 0 & $0,02 \pm 0,01$ \\
\hline 4 & $0,41 \pm 0,02$ & $0,71 \pm 0,02$ & $0,16 \pm 0,03$ \\
\hline
\end{tabular}


Таблиця 2 - Результати візуалізації мілнаципрану та продуктів його біотрансформації за допомогою хромогенних реактивів

\begin{tabular}{|c|c|c|c|}
\hline \multirow{2}{*}{ Реактив } & \multicolumn{3}{|c|}{ Забарвлення } \\
\hline & мілнаципран & N-дезетилмілнаципран & мінорний метаболіт \\
\hline Драгендорфа & Оранжеве & Оранжеве & Оранжеве \\
\hline $\begin{array}{l}\text { Підкислений } \\
\text { калій йодплатинат }\end{array}$ & Синьо-фріолетове & Синьо-сріолетове & Синьо-фріолетове \\
\hline Ван-Урка & Жовте & H.3. & Жовте \\
\hline Нінгідрин & Рожево-фріолетове & Червоно-сріолетове & Червоно-фріолетове \\
\hline Манделіна & H.3. & H.3. & H.3. \\
\hline Меркурій (II) нітрат & Сине & H.3. & H.3. \\
\hline Фреде & H.3. & H.3. & H.3. \\
\hline Лібермана & $\begin{array}{c}\text { Жовте, що змінюється } \\
\text { на оранжеве }\end{array}$ & Оранжеве & Оранжеве \\
\hline Ердмана & H.3. & H.3. & H.3. \\
\hline Маркі & Буро-коричневе & Коричневе & Жовто-коричневе \\
\hline $\begin{array}{l}\text { Кислота сульфратна } \\
\text { концентрована }\end{array}$ & H.3. & H.3. & H.3. \\
\hline
\end{tabular}

Примітка. Н.з. - немає забарвлення.

(Нідерланди), обладнаний подвійним квадрупольним мас-аналізатором, іонізація електронним ударом (Еi=70 eB). При цьому здійснювали пряме введення проби до іонної камери, а дослідження виконували в режимі повного сканування іонів. Хромато-мас-спектрометричні дослідження було проведено в науково-технологічному комплексі "Інститут монокристалів" Національної академії наук України.

РЕЗУЛЬТАТИ Й ОБГОВОРЕННЯ. ПрОбИ біорідини збирали, враховуючи дані літератури про екскреції мілнаципрану. Біотранссормація мілнаципрану переважно відбувається за 2 сразою метаболізму з утворенням глюкуронідів, певна кількість нативної речовини піддається $N$-деалкілуванню [5, 6].

Для хроматограсрічного дослідження елюатів використовували чотири рухомі фрази з переліку тих, які рекомендувала Міжнародна асоціація судових токсикологів (TIAFT) для проведення загального ТШХ-скринінгу наркотичних та сильнодіючих речовин. За рекомендаціями TIAFT, одночасне застосування не менше трьох рухомих фраз, бажано з низькою кореляцією значень $R_{\mathrm{f}}$, забезпечує надійне виявлення досліджуваної речовини при токсикологічному скринінгу [5]. Придатність обраних рухомих фраз для виявлення мілнаципрану в екстрактах із сечі ми показали в попередніх дослідженнях із ТШХ-скринінгу цього препарату за наявності ряду лікарських речовин антидепресивної дії [8].

На хроматограмах гідролізатів сечі ми детектували нативну речовину і два продукти метаболічних перетворень мілнаципрану: основний метаболіт - N-дезетилмілнаципран та мінорний метаболіт, ідентифрікувати який не вдалося через низьку інтенсивність аналітичного сигналу на фроні “шуму" матричних компонентів (див. табл. 1, 2).
Як видно, продукти взаємодії мілнаципрану і його метаболітів 3 нінгідрином та реактивом Лібермана мали однакове забарвлення, що було селективним відносно біогенних компонентів матриці. Нативна речовина також утворювала селективне забарвлення з насиченим розчином меркурій (II) нітрату. У попередніх дослідженнях зі стандартними розчинами мілнаципрану в етанолі ми встановили чутливість виявлення препарату за допомогою хромогенних реактивів (мкг у пробі): 5,0 мкг (реактив Драгендорфа), 1,0 мкг (підкислений калій йодплатинат), 3,0 мкг (реактив Ван-Урка), 4,0 мкг (розчин нінгідрину), 6,0 мкг (насичений розчин меркурій (II) нітрату), 5,0 мкг (реактив Лібермана), 3,0 мкг (реактив Маркі).

Нативну речовину, виділену із сечі, та основний метаболіт мілнаципрану (за розміром плями на хроматограмах) ідентифікували методом мас-спектрометрії, використовуючи бібліотеку мас-спектрів NIST 08, та за молекулярною масою, яку визначали за розташуванням відповідних молекулярних піків у мас-спектрах (рис. 1, 2).

ВИСНОВКИ. Запропоновано умови детектування мілнаципрану і його метаболітів у сечі людини за допомогою методу ТШХ після прийняття разової терапевтичної дози антидепресанту. Встановлено параметри хроматограсрічної рухливості основного (N-дезетилмілнаципран) та мінорного метаболітів мілнаципрану в чотирьох скринінгових ТШХ-системах, а також результати реакцій їх візуалізації хромогенними реактивами. Методики рекомендовано для використання у практиці судової та клінічної токсикології.

Конфрлікт інтересів. Автори підтверджують відсутність консрлікту інтересів у цій публікації. 


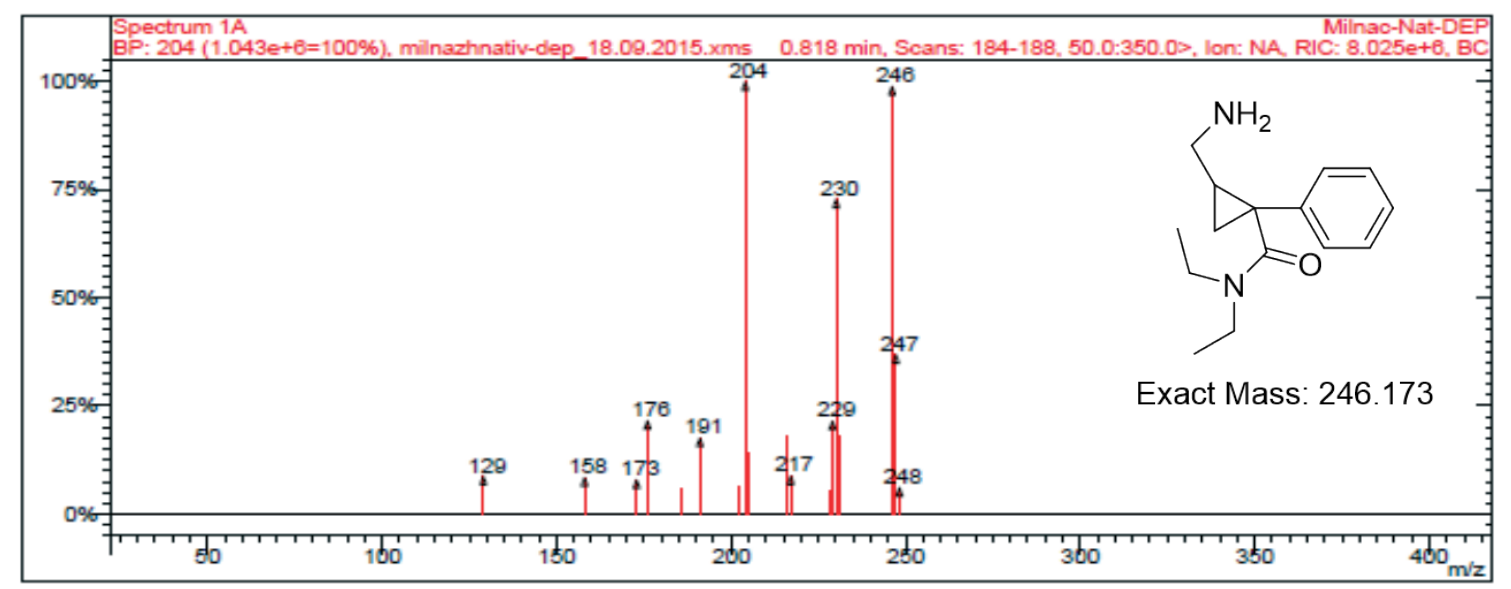

Рис. 1. Мас-спектр мілнаципрану, екстрагованого із сечі (основні іони m/z 204, 246, 230, 247, 176, 229, 191, 129, 217 , $158,179,248)$.

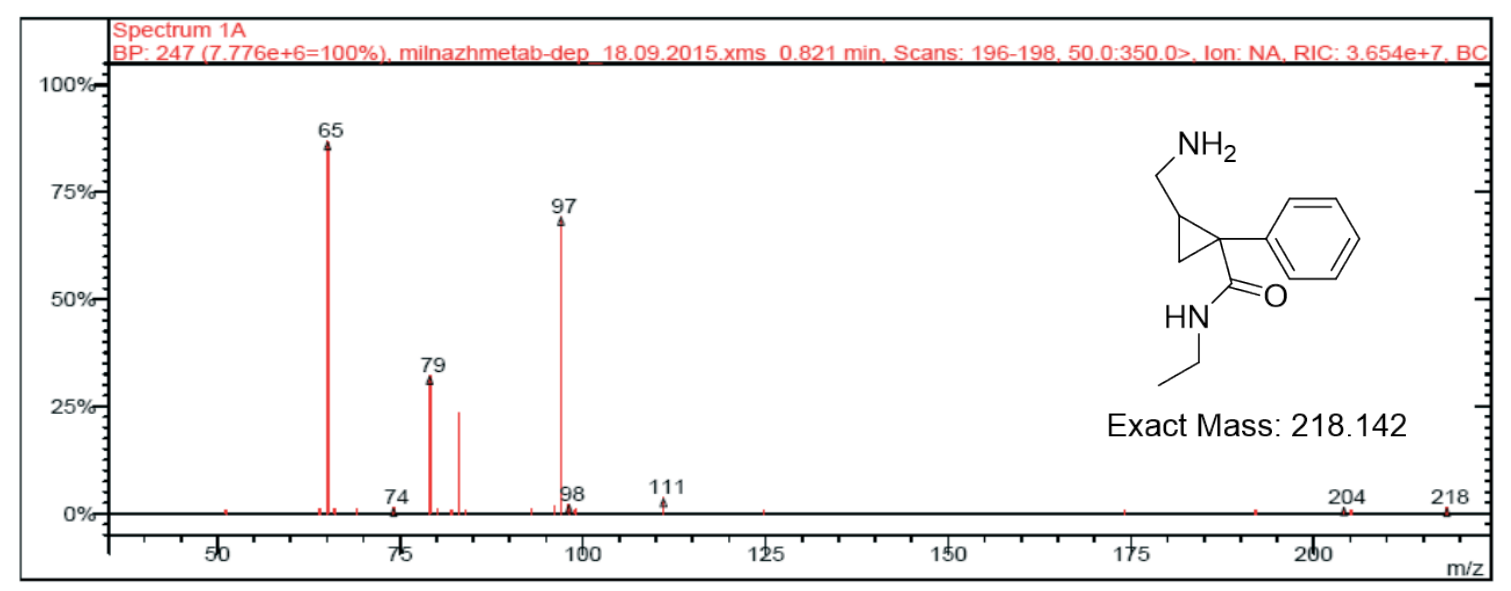

Рис. 2. Мас-спектр основного метаболіту мілнаципрану - N-дезетилмілнаципрану (основні іони m/z 65, 97, 79, 83, $111,98,74,204,218)$.

\section{СПИСОК ЛІТЕРАТУРИ}

1. Serotonin-norepinephrine reuptake inhibitors and the influence of binding affinity (Ki) on analgesia / $\mathrm{M}$. Raouf, A. J. Glogowski, J. J. Bettinger, J. Fudin // J. Clin. Pharm. Ther. - 2017. - 42. - P. 513-517.

2. Машковский М. Д. Лекарственные средства / М. Д. Машковский. - 16-е изд., перераб., испр. и доп. М. : Новая Волна, 2020. - 1216 с.

3. Levine M. Cardiotoxicity and serotonin syndrome complicating a Milnacipran overdose / M. Levine, A. T. Carry, A. Connor // J. Med. Toxicol. - 2011. - 7, No. 4. - P. 312-316.

4. Fanton L. Fatal intoxication with milnacipran / L. Fanton, F. Bevalot, H. Grait // J. Forensic Leg. Med. 2008. - 15, No. 6. - P. 388-390.

5. MoffatA. C. Clarke's analysis of drugs and poisons in pharmaceuticals, body fluids and postmortem material /
A. C. Moffat, M. D. Osselton, B. Widdop. - 4-th ed. London, Chicago: Pharmaceutical Press, 2011. - 2736 p.

6. Excretion and metabolism of milnacipran in humans after oral administration of milnacipran hydrochloride / F. Li, C. Chin, J. Wangsa, J. Ho // Drug. Metab. Dispos. - 2012. - 40, No. 9. - P. 1723-1735.

7. Kanalaa K. Bioanalytical method development and validation of milnacipran in rat plasma by LC-MS/MS detection and its application to a pharmacokinetic study / K. Kanalaa, N. T. Hwisac, B. R. Chanduc // J. Pharm. Anal. - 2013. - 3, No. 6. - P. 481-488.

8. Баюрка С. В. Аналітична діагностика отруєнь мілнаципраном / С. В. Баюрка, С. А. Карпушина, В. П. Мороз // Клініч. фрармація. - 2016. - 20, № 4. C. 62-65. 


\section{REFERENCES}

1. Raouf, M., Glogowski, A.J., Bettinger, J.J., \& Fudin, J. (2017). Serotonin-norepinephrine reuptake inhibitors and the influence of binding affinity (Ki) on analgesia. J. Clin. Pharm. Ther., 42, 513-517.

2. Mashkovskii, M.D. (2020). Medicines. Moscow: Izdatelstvo Novaya Volna [in Russian].

3. Levine, M., Carry, A.T., \& Connor, A. (2011). Cardiotoxicity and serotonin syndrome complicating a Milnacipran overdose. J. Med. Toxicol., 7 (4), 312-316.

4. Fanton, L., Bevalot, F., \& Grait, H. (2008). Fatal intoxication with milnacipran. J. Forensic Leg. Med., 15 (6), 388-390.

5. Moffat, A.C., Osselton, M.D., \& Widdop, B. (2011). Clarke's analysis of drugs and poisons in pharmaceuticals, body fluids and postmortem material. (4-th ed.). London, Chicago: Pharmaceutical Press.

6. Li, F., Chin, C., Wangsa, J., \& Ho, J. (2012). Excretion and metabolism of milnacipran in humans after oral administration of milnacipran hydrochloride. Drug. Metab. Dispos., 40 (9), 1723-1735.

7. Kanalaa, K., Hwisac, N.T., \& Chanduc, B.R. (2013). Bioanalytical method development and validation of milnacipran in rat plasma by LC-MS/MS detection and its application to a pharmacokinetic study. J. Pharm. Anal., 3 (6), 481-488.

8. Baiurka, S.V., Karpushyna, S.A., \& Moroz, V.P. (2016). Analytical diagnosis of milnacipran poisoning. Clin. Pharmacy, 20 (4), 62-65.
S. V. Baiurka, S. A. Karpushyna, E. Yu. Akhmedov NATIONAL UNIVERSITY OF PHARMACY, KHARKIV

\section{DETECTION OF MILNACIPRAN BIOTRANSFORMATION PRODUCTS IN URINE UNDER TLC-SCREENING}

\section{Summary}

Introduction. Thin layer chromatography screening is the most accessible type of screening procedure that is used in forensic toxicology. For the analytical diagnosis of drug poisoning by the TLC method, it is important to develop conditions for the detection of both native compounds and products of their biotransformation in the biological samples.

The aim of the study - to develop a method for isolating the antidepressant drug milnacipran from human urine in the presence of its biotransformation products and determine the conditions for their detection by thin layer chromatography, suitable for analytical diagnostics of thymoleptic intoxication.

Research Methods. The study was carried out with human urine samples collected after taking a single therapeutic dose of milnacipran. The urine was subjected to the acid hydrolysis and the antidepressant and its metabolites were extracted from the destructate with chloroform from an alkaline medium at $\mathrm{pH}$ 8-9. Concomitant endogenous admixtures were removed by extraction with diethyl ether from an acidic medium at $\mathrm{pH}$ 1. For the chromatographic study of the extracts, four mobile phases recommended by the International Association of Forensic Toxicologists for TLC screening of drugs, and Merk chromatographic plates were used. Colour reactions were carried out on pieces of chromatographic plates with a range of chromogenic reagents most common used in chemicaltoxicological analysis. Metabolites were identified by electron impact mass spectrometry.

Results and Discussion. The parameters of the chromatographic mobility of the main ( $N$-desethylmylnacipran) and minor (the structure could not be established) metabolites of milnacipran were determined, as well as the results of the reactions of their visualization with chromogenic reagents.

Conclusions. Isolation conditions for milnacipran and its biotransformation products from human urine have been proposed. The method of the detection of the native compound and milnacipran metabolites in the extracts from urine by TLC and colour reactions after taking a single therapeutic dose of the drug has been developed. The methods are recommended for use in the practice of forensic and clinical toxicology.

KEY WORDS: milnacipran; chemical-toxicological analysis; biofluids; metabolites; thin layer chromatography; color reactions; mass spectrometry.

Отримано 08.11.21

Адреса для листування: С. А. Карпушина, Національний фрармацевтичний університет Міністерства охорони здоров'я України, вул. Пушкінська, 53, Харків, 61002, Україна, e-mail: svitkrp@gmail.com. 